\title{
Restraint Use in Older Adults Receiving Home Care
}

\author{
Kristien Scheepmans, MSN, RN, *广 Bernadette Dierckx de Casterlé, PhD, RN, ${ }^{\dagger}$ Louis Paquay, MSN, \\ RN, *Hendrik Van Gansbeke, MSN, RN, * and Koen Milisen, PhD, RN ${ }^{\dagger \neq}$
}

OBJECTIVES: To determine the prevalence, types, frequency, and duration of restraint use in older adults receiving home nursing care and to determine factors involved in the decision-making process for restraint use and application.

DESIGN: Cross-sectional survey of restraint use in older adults receiving home care completed by primary care nurses.

SETTING: Homes of older adults receiving care from a home nursing organization in Belgium.

PARTICIPANTS: Randomized sample of older adults receiving home care $(\mathrm{N}=6,397$; mean age $80.6 ; 66.8 \%$ female).

MEASUREMENTS: For each participant, nurses completed an investigator-constructed and -validated questionnaire collecting information demographic, clinical, and behavioral characteristics and aspects of restraint use. A broad definition of restraint was used that includes a range of restrictive actions.

RESULTS: Restraints were used in $24.7 \%$ of the participants, mostly on a daily basis $(85 \%)$ and often for a long period $(54.5 \%, 24 \mathrm{~h} / \mathrm{d})$. The most common reason for restraint use was safety $(50.2 \%)$. Other reasons were that the individual wanted to remain at home longer, which necessitated the use of restraints $(18.2 \%)$ and to provide respite for the informal caregiver $(8.6 \%)$. The latter played an important role in the decision and application process. The physician was less involved in the process. In $64.5 \%$ of cases, there was no evaluation after restraint use was initiated.

From the "Nursing Department, Wit-Gele Kruis van Vlaanderen, Brussels; 'Department of Public Health and Primary Care, Academic Centre for Nursing and Midwifery, KU Leuven; and "Division of Geriatric Medicine, Department of Internal Medicine, Leuven University Hospitals, Leuven, Belgium.

The results in this paper were part of an oral presentation at the symposium, "Behind Closed Doors: Physical Restraint Use in Home Care," presented at the Gerontological Society of America Congress 2014, November 5-9, Washington, DC.

Address correspondence to Koen Milisen, Department of Public Health and Primary Care, Academic Centre for Nursing and Midwifery, KU Leuven, Kapucijnenvoer 35 blok d-bus 7001, Leuven B-3000, Belgium.

E-mail: koen.milisen@kuleuven.be

DOI: $10.1111 /$ jgs. 14880
CONCLUSION: Use of restraints is common in older adults receiving home care nursing in Belgium. These results contribute to a better understanding of the complexity of use of restraints in home care, a situation that may be even more complex than in nursing homes and acute hospital settings. J Am Geriatr Soc 2017.

Key words: restraints; home care nursing; prevalence; older adults; decision-making process

$\mathbf{R}$ estraint use in older adults is complex. Evidence from acute and this is not a good adaptation. By residential setting we mean the nursing homes settings shows that restraint use has many negative consequences. Patients experience physical (e.g., incontinence, decubitus ulcers, falls), psychological (e.g., depression, anger), and social (e.g., social isolation) consequences. ${ }^{1,2}$ The use of restraints also affects the family (e.g., idea of finality, denial) and healthcare workers (e.g., inner conflicts and mixed emotions such as frustration, guilt). ${ }^{3}$ Restraints are still frequently used in many countries in hospitals ${ }^{4-6}$ and nursing homes. ${ }^{7-9}$ In Belgian hospitals, $35 \%$ of nurses indicated that fewer than $10 \%$ of patients had been restrained during the previous week, $25 \%$ that $10 \%$ to $19 \%$ had been restrained, and $15 \%$ that $20 \%$ to $69 \%$ had been restrained. ${ }^{10}$ In Belgian nursing homes, physical restraints are used at least once in $47.5 \%$ of the residents, with prevalence rates at the unit level varying from $5 \%$ to $90 \%$. $^{11}$

Research on restraint use in home care is scarce. In two studies on community-dwelling older persons with cognitive impairment, the prevalence of physical restraint use was $9.9 \%$ (range $3.4-19.8 \%$ across several countries assessed $)^{12}$ and $7 \% .^{13}$ Another study used a self-report survey of home care nurses and found that almost $80 \%$ of these nurses had used physical restraints at least once. ${ }^{14} \mathrm{In}$ Belgium, there are no prevalence studies on restraint use in home care; only one qualitative study is available. ${ }^{15}$ That study not only provided evidence of the use of restraints, but also suggested that the subject of restraint use in home care may be more complex than in nursing homes and hospitals. Their findings revealed that nurses are unclear 
about the concept of restraint use in home care and that there are many unanswered questions about related ethical and legal responsibilities.

In Belgium, there is no specific legislation regulating the use of (physical) restraints in any setting, but restraining or isolating an individual is considered deprivation of freedom and is forbidden. Belgian law clearly defines who may deprive a person's freedom. A judge can decide about a forced admission to a healthcare facility. In the context of providing healthcare, only nurses and medical doctors may apply restraints.

Because of the global demographic shift toward an aging population, an increasing percentage of frail older people will receive in-home care. Healthcare workers will increasingly be confronted with the possibility of restraint use in home care and will have to assess the associated implications.

Understanding of the use of restraints in home care will enhance support of healthcare workers. When using the term "restraint," a range of restrictive actions that limit an individual's freedom is included.

The main objective of this study was to acquire more detailed data on restraint use in home care, which will aid in the development of an evidence-based practice guideline that will inform healthcare professionals on how to avoid or reduce restraint use in home care. More specifically, the goal was to answer the following research questions: What are the prevalence, types, frequency, and duration of restraint use in older adults receiving home care? What factors underlie the decision-making process and application of restraints in home care (e.g., reasons, involved persons, permission, documentation in the record, evaluation of restraint outcomes)?

\section{METHODS}

\section{Design}

A cross-sectional survey was conducted with home care nurses caring for individuals aged 60 and older in WitGele Kruis. The nurses assessed restraint use of their patients.

\section{Study Setting and Sample}

\section{Study Setting}

The Wit-Gele Kruis is a nonprofit organization that provides person-centered nursing care at home in Flanders (Belgium). Professional home care nursing is part of the social security system in Belgium and is financed by the National Institute for Health and Disability Insurance. In Belgium, health insurance is mandatory and guarantees reimbursement for individuals who need home care nursing. ${ }^{15}$ The Wit-Gele Kruis comprises five autonomous provincial organizations and is spread over 102 divisions. Of these, all but one contributed older adults to the study.

\section{Sample}

To select the study subjects, each provincial organization created a database of all adults aged 60 and older receiving home care from the Wit-Gele Kruis during the month of March 2013. No other inclusion or exclusion criteria were specified. Eight thousand subjects $(17.5 \%)$ were randomly selected from 45,700 older adults in the database using a randomization algorithm.

\section{Questionnaire}

\section{Development}

A new questionnaire for use by clinical home care nurses was developed based on findings in published literature ${ }^{14}$ and insights from a previous qualitative study on restraint use in home care. ${ }^{15}$ That study suggested relevant items to be included, for example, a list of the types of restraints used, the reasons for using restraints in home care, and the persons involved in the decision-making process. The source of the data derives from a combination of information retrieved from electronic health records and the questionnaire that the nurses completed based on their knowledge of individuals under their care.

Experts iteratively assessed content validity of the questionnaire until consensus was reached. First, the questionnaire was presented to the nursing directors of the five provincial organizations. Based on their recommendations, the questionnaire was adapted by the research team and evaluated again by the nursing directors and two international researchers with expertise in restraint use in the elderly. Finally, clinical nurses of one division assessed the clarity, completeness, and comprehensiveness of the questionnaire, as well as the procedure for data collection and the cover letter with instructions, and adjusted accordingly.

\section{Variables}

The questionnaire consisted of items sampling participant demographic and clinical variables and variables concerning use of restraints.

Demographic and Clinical Variables. For the demographic and clinical variables, existing validated scales from the Resident Assessment Instrument (RAI) (e.g., Cognitive Performance Scale for home care) were used in the questionnaire. $^{16-18}$ Data related to age, sex, and care dependency (based on Belgian Activity of Daily Living Evaluation Scale-Katz Index scores) ${ }^{19}$ were extracted from participants' records. The degree of an individual's dependence on care is subdivided into four categories $(0$, $\mathrm{A}, \mathrm{B}, \mathrm{C})$, and reimbursement is based on his or her indicated category. This ranges from physically independent (0) to physically dependent for all daily activities (C) (Table 1). ${ }^{20}$

Other variables measured were the individual's living situation (alone vs with another), hospitalization in the past 3 months, polypharmacy (taking $\geq 5$ different medications), number of falls during the previous 6 months, and fall risk (estimation of the risk of falling according to the nurse's clinical judgment). ${ }^{21}$ Cognitive function was assessed using the Cognitive Performance Scale for home care. ${ }^{16-18}$ A score of 2 or more on this scale indicates cognitive impairment. ${ }^{22}$ Behavioral symptoms (Table 1 ) were measured using a 4-point scale from the RAI ${ }^{23}$ and divided 
Table 1. Demographic and Clinical Characteristics of Sample $(\mathrm{N}=6,397)$

\begin{tabular}{|c|c|}
\hline Characteristic & Value \\
\hline Age, mean $\pm S D(n=6,375)$ & $80.6 \pm 7.8$ \\
\hline Female, $n(\%)(n=6,388)$ & $4,268(66.8)$ \\
\hline \multicolumn{2}{|l|}{ Care dependence category, $\mathrm{n}(\%)(\mathrm{n}=6,368)^{\mathrm{a}}$} \\
\hline 0 & $3,341(52.5)$ \\
\hline A & $1,669(26.2)$ \\
\hline B & $1,094(17.2)$ \\
\hline C & $264(4.1)$ \\
\hline Living alone, $n(\%)(n=6,285)$ & $2,917(46.4)$ \\
\hline Informal caregiver, $\mathrm{n}(\%)(\mathrm{n}=5,978)^{\mathrm{b}}$ & $4,186(70.0)$ \\
\hline \multicolumn{2}{|c|}{ Well-being and perceived support of informal caregiver, $\mathrm{n}(\%)$} \\
\hline $\begin{array}{l}\text { Is able to care for the patient in the future } \\
(\mathrm{n}=4,062)\end{array}$ & $3,469(85.4)$ \\
\hline $\begin{array}{l}\text { Expresses feeling of sadness, anger, depression } \\
(n=3,636)\end{array}$ & $643(17.7)$ \\
\hline $\begin{array}{l}\text { Is upset by disease or condition of the patient } \\
(n=3,580)\end{array}$ & $471(13.2)$ \\
\hline $\begin{array}{l}\text { Is dissatisfied with the support of family/friends } \\
(n=3,576)\end{array}$ & $245(6.9)$ \\
\hline $\begin{array}{l}\text { Is dissatisfied about the professional support } \\
(\mathrm{n}=3,557)\end{array}$ & $106(3.0)$ \\
\hline$\geq 5$ medications, $n(\%)(n=5,750)$ & $3,190(55.5)$ \\
\hline $\begin{array}{l}\text { Participant hospitalized within previous } 3 \text { months, } n(\%) \\
(n=6,057)\end{array}$ & $1,121(18.5)$ \\
\hline Cognitive impairment, $n(\%)(n=5,867)$ & $1,730(29.5)$ \\
\hline \multicolumn{2}{|l|}{ Behavioral symptoms, $n(\%)(n=6,397)$} \\
\hline Wandering & $441(6.9)$ \\
\hline Verbal violence & $377(5.9)$ \\
\hline Physical violence & $144(2.3)$ \\
\hline Socially inappropriate or disruptive behavior & $220(3.4)$ \\
\hline Public undressing or inappropriate sexual behavior & $66(1)$ \\
\hline Resisting care & $477(7.5)$ \\
\hline \multicolumn{2}{|l|}{ Behavioral problems, $n(\%)(n=5,711)$} \\
\hline No & $5,342(93.5)$ \\
\hline$<$ Daily & $179(3.1)$ \\
\hline Daily & $190(3.3)$ \\
\hline \multicolumn{2}{|l|}{ Falls, n (\%) } \\
\hline Fall within past 6 months $(n=6,067)$ & $1,841(30.3)$ \\
\hline Estimated risk of falling by nurse $(n=6,282)$ & $3,670(58.4)$ \\
\hline
\end{tabular}

$\mathrm{N}$ differs for each variable depending on how many nurses completed the answer for that variable.

${ }^{\mathrm{a}}$ Defined according to Steeman et al. ${ }^{20}$ : Category 0, physically independent; Category A, physically dependent on help for bathing, dressing, transferring, or using the toilet; Category B, physically dependent on help for bathing, dressing, transferring, using the toilet, maintaining continence, or feeding; Category C, physically dependent on help for bathing, dressing, transferring, using the toilet, maintaining continence, and feeding.

${ }^{\mathrm{b}}$ Informal care is described as "the mutual, self-evident, unpaid, non-organized help within families and a social network." 31

into three categories: no behavioral problems, one or more behavioral problems less than daily, and one or more behavioral problems daily. Finally, the presence of informal care (yes/no) was evaluated, and the well-being and perceived support of the informal caregiver were assessed using six questions adapted from the RAI (Table 1). ${ }^{23}$

Restraint Variables. No consistent definition of restraint use can be found in the available literature. For the present study, therefore, restraint use was defined broadly to include not only devices, but also other restrictive actions, as described below. This definition was based on the results of a qualitative study of restraint use in home care in Belgium ${ }^{15}$ and on the definition from another study. ${ }^{24}$ To ensure that all types of restraints were sampled, any other actions that healthcare workers or informal caregivers performed that restricted the individual's freedom in some way (e.g., adaptation of the house, removal of aids such as a walker) were included in the definition (Table 2). In the context of this liberal definition of restraint use, nurses were asked (in the questionnaire) how many times they had observed or used each type of restraint during the past month.

For the assessment, the frequency of restraint use in the past month was categorized as once a month, more than once a month but not daily, or daily. The duration of restraint use was estimated using six categories ranging from less than 30 minutes a day to 24 hours a day (Table 2).

The various categories of persons involved included the initiator (person requesting restraints), the persons involved in the decision-making process (those making the final decision), and the person executing the restraints. Examples of the various categories of involved persons are informal caregiver, nurse, nurses' aide, domestic aide, physician (general practitioner), and multidisciplinary team. The nine reasons for using restraints were requested by the individual; requested by the informal caregiver; ensuring the safety of the individual; protecting the environment from damage or disruption by the individual; respite for informal caregivers; absence of the informal caregiver; absence of professional help; the individual wanted to remain at home longer, which necessitated the use of restraints; and desire to delay admission to a nursing home. Multiple types of answers were acceptable for the variables "frequency," "reasons," and "persons involved."

Participant permission to use restraints: oral and written permission, oral permission, no permission requested, regardless of ability to do so, cognitively or physically unable to give permission. Permission of the family: individual written permission given, oral permission given, no permission requested, and refused to grant permission.

A 4-point Likert scale was used to assess the frequency of restraints documented in the medical record (never, sometimes, regularly, always) and to assess restraint outcomes (never, daily, weekly, monthly).

\section{Data Collection}

Each questionnaire was identified using a unique label containing basic information (participant number, name, address) and the name of the primary nurse. This primary nurse completed the questionnaire with input from colleagues during weekly discussions. The nurses had 2 weeks to complete the questionnaire. There were no incentives (financial or otherwise) for nurses to participate. Nurses and head nurses received a cover letter containing a description of the study objectives and detailed instructions on how to complete the questionnaire. All questionnaires were scanned using automatic data extraction, and the data were anonymized.

\section{Analysis}

The database was assessed for missing data, correct database coding, and extreme values (outliers). Data were analyzed using descriptive statistics using SAS version 9.3 
Table 2. Types, Reasons, Frequency, and Duration of Restraint Use

\begin{tabular}{|c|c|c|}
\hline Characteristics of restraints & n (\%) & $\begin{array}{c}95 \% \\
\text { Confidence } \\
\text { Interval }\end{array}$ \\
\hline \multicolumn{3}{|l|}{ Type of restraint $(n=1577)$} \\
\hline Bed against wall & $615(39.0)$ & $36.6-41.5$ \\
\hline Adaptation of house & $406(25.8)$ & $23.6-28.0$ \\
\hline Bedrails & $380(24.1)$ & $22.0-26.3$ \\
\hline Tilted chair or geriatric chair & $255(16.2)$ & $14.4-18.1$ \\
\hline Brakes on wheelchair & $220(14.0)$ & $12.3-15.8$ \\
\hline Locking house & $208(13.2)$ & $11.6-15.0$ \\
\hline Electronic supervision & $178(11.3)$ & $9.8-12.9$ \\
\hline Removal of aids (e.g., walker) & $169(10.7)$ & $9.2-12.3$ \\
\hline Chair against table & $150(9.5)$ & $8.1-11.1$ \\
\hline Gloves & $110(7.0)$ & $5.8-8.3$ \\
\hline Appropriate clothing & $83(5.3)$ & $4.2-6.5$ \\
\hline Over-chair table & $75(4.8)$ & $3.8-5.9$ \\
\hline $\begin{array}{l}\text { Forced or camouflaged medication } \\
\text { administration }\end{array}$ & $73(4.6)$ & $3.6-5.8$ \\
\hline Belts & $41(2.6)$ & $1.9-3.5$ \\
\hline $\begin{array}{l}\text { Separation in a room without } \\
\text { locking the door }\end{array}$ & $40(2.5)$ & $1.8-3.4$ \\
\hline Locking the room & $37(2.4)$ & $1.7-3.2$ \\
\hline $\begin{array}{l}\text { Restraints during activities of daily } \\
\text { living }\end{array}$ & $38(2.4)$ & $1.7-3.3$ \\
\hline Restraint vest & $13(0.8)$ & $0.4-1.4$ \\
\hline Sleeping bag & $11(0.7)$ & $0.3-1.2$ \\
\hline Ankle and wrist ties & $11(0.7)$ & $0.3-1.2$ \\
\hline Nursing blanket ${ }^{\mathrm{a}}$ & $3(0.2)$ & $0.04-0.55$ \\
\hline Other & $47(3.0)$ & $2.2-3.9$ \\
\hline \multicolumn{3}{|l|}{ Reason for restraint $(n=1,577)$} \\
\hline Safety of patient & $791(50.2)$ & $47.7-52.7$ \\
\hline Request of informal caregiver & $503(31.9)$ & $29.6-34.3$ \\
\hline Request of patient & $295(18.7)$ & $16.8-20.7$ \\
\hline $\begin{array}{l}\text { Patient wanted to remain at home } \\
\text { longer, which necessitated use of } \\
\text { restraint }\end{array}$ & $287(18.2)$ & $16.3-20.2$ \\
\hline Respite for the informal caregiver & $136(8.6)$ & $7.3-10.1$ \\
\hline $\begin{array}{l}\text { Protecting environment from } \\
\text { damage or disruption by patient }\end{array}$ & $125(7.9)$ & $6.6-9.4$ \\
\hline $\begin{array}{l}\text { Desire to delay an admission to } \\
\text { nursing home }\end{array}$ & $120(7.6)$ & $6.3-9.0$ \\
\hline Absence of the informal caregiver & $105(6.7)$ & $5.5-8.0$ \\
\hline Absence of professional help & $34(2.2)$ & $1.5-3.0$ \\
\hline Other & $43(2.7)$ & $2.0-3.7$ \\
\hline \multicolumn{3}{|l|}{ Frequency of restraint $(n=1,285)$} \\
\hline Once a month & $77(6.0)$ & $4.8-7.4$ \\
\hline$>$ 0nce a month but not daily & $78(6.1)$ & $4.8-7.5$ \\
\hline Daily & $1,130(87.9)$ & $86.0-89.7$ \\
\hline \multicolumn{3}{|l|}{ Duration of restraint $(n=1,157)$} \\
\hline$<30$ minutes & $123(10.6)$ & $8.9-12.5$ \\
\hline$<30-59$ minutes & $24(2.1)$ & $1.3-3.1$ \\
\hline $1-2$ hours & $30(2.6)$ & $1.8-3.7$ \\
\hline 3-6 hours & $38(3.3)$ & $2.3-4.5$ \\
\hline$>7$ hours & $312(27.0)$ & $24.4-29.6$ \\
\hline 24 hours per day & $630(54.5)$ & $51.5-57.3$ \\
\hline
\end{tabular}

${ }^{\mathrm{a}} \mathrm{A}$ nursing blanket is used to tightly cover someone to restrict his or her movements.

(SAS Institute, Inc., Cary, NC). Categorical data were expressed as number of cases and percentages. Continuous data were expressed as means with standard deviations. Percentages were calculated based on the actual number of answers.

\section{Ethical Approval}

The Medical Ethics Committee of the Leuven University Hospitals approved the study and procedures (no. B322201317586). According to Belgian law and the Declaration of Helsinki, no informed consent of participants or family members was necessary because the study used anonymous data and did not influence the daily care that participants received.

\section{RESULTS}

\section{Sample}

Of 8,000 questionnaires sent out to nurses, 7,688 were returned. Of these, 972 were not completed for various reasons, leaving 6,716 questionnaires for analysis (Figure 1). Questions on restraint use start with question 8 of the questionnaire: "Which restraints were used in the past month?" When this question was left blank $(\mathrm{n}=319)$, the entire questionnaire was excluded from further analysis because the data were meaningless for study objectives. Thus, of the 8,000 questionnaires, $6,397(80 \%)$ were available for analysis (Figure 1 ).

The mean age of these 6,397 patients was $80.6 \pm 7.8$ (Table 1); $66.8 \%$ were female, $46.4 \%$ lived alone, and $47.5 \%$ were dependent in some level of care (categories A-C). In $70 \%$ of cases, there was an informal caregiver involved. More than half of the patients $(55.5 \%)$ were taking more than five different medications (polypharmacy), and $18.5 \%$ had been hospitalized during the past 3 months. Almost one-third (29.5\%) had cognitive impairment, and $6.4 \%$ had behavioral problems. One-third had fallen during the past 6 months, and $58.4 \%$ had a high fall risk, as estimated by the nurses.

\section{Prevalence and Types of Restraints}

Using a broad definition of restraint, it was determined that restraints were used in 1,577 participants $(24.7 \%$, $95 \%$ confidence interval $(\mathrm{CI})=23.6-25.7 \%)$. The most common types of restraints were bed against the wall $(39,0 \%)$ and adaptation of the house $(25.8 \%)$. The least common types of restraints were the nursing blanket $(0.2 \%)$ and the ankle and wrist ties and the sleeping bag (both $0.7 \%$ ). (Table 2).

\section{Frequency and Duration of Use}

Most restraints were used daily $(87.9 \%)$. More than half of the patients $(54.5 \%)$ were restrained for 24 hours per day 7 days per week and $27 \%$ for more than 7 hours a day (Table 2).

\section{Reasons for Use}

The main reasons reported for using restraints were the safety of the participant $(50.2 \%)$; request of the informal caregiver $(31.9 \%)$; participant request $(18.7 \%)$; participant wanted to remain at home longer, which necessitated the 


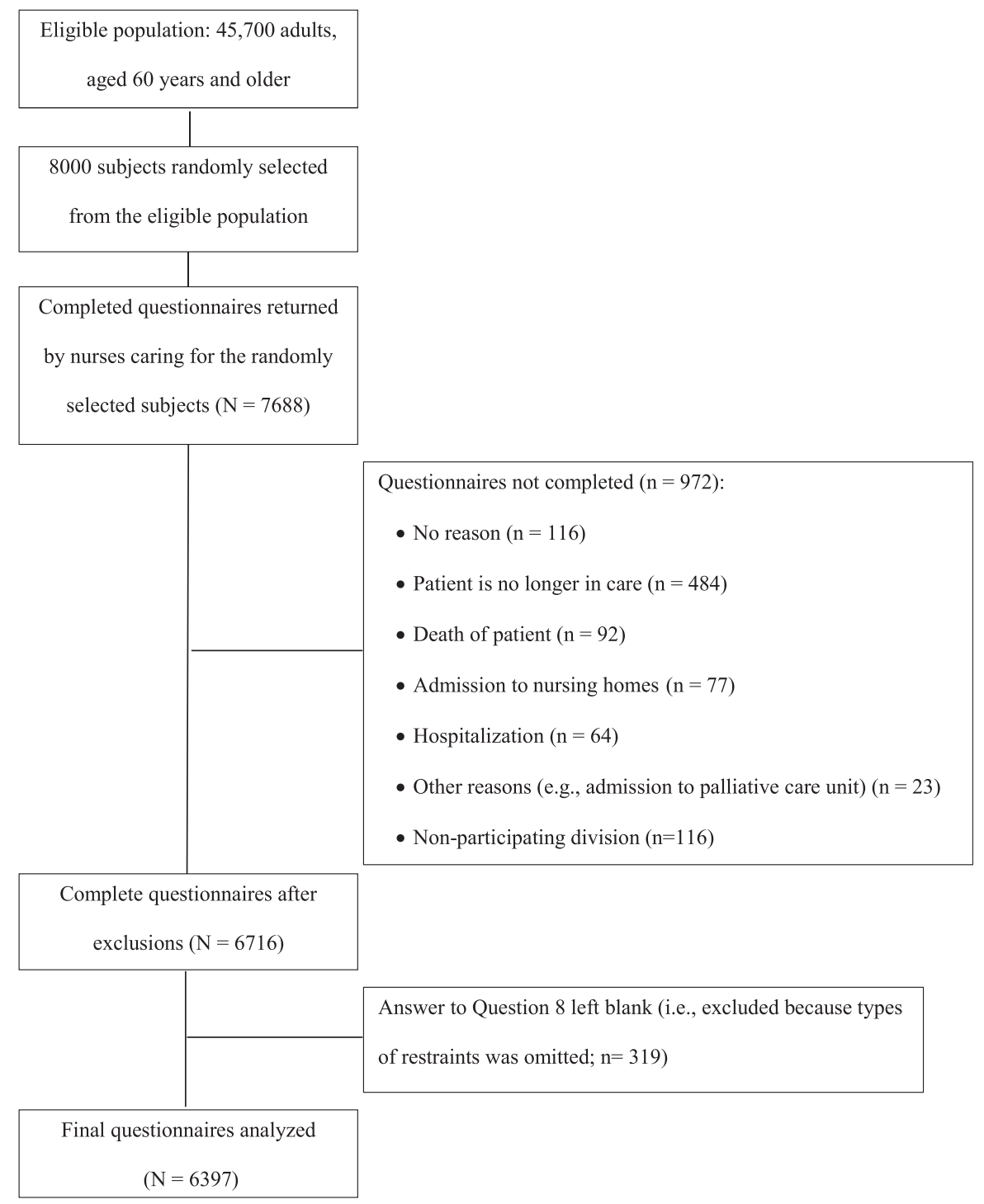

Figure 1. Study flowchart.

use of restraints $(18.2 \%)$; and to give the informal caregiver respite $(8.6 \%)$ (Table 2$)$.

\section{Persons Involved with Restraint Use}

The informal caregiver $(55.3 \%)$, nurse $(37.2 \%)$, and the older adult $(24.9 \%)$ most frequently asked for use of restraints. In $11.9 \%$ of the cases, the physician was the initiator. The informal caregiver $(62 \%)$, older adult $(42.9 \%)$, and nurse $(39.2 \%)$ were most commonly involved in the decision to use restraints. Again, the physician was less frequently involved in the decision $(16.2 \%)$ (Table 3$)$.

Informal caregivers $(60.7 \%)$ and nurses $(42.2 \%)$ most often executed the restraints. Nursing aides $(7.9 \%)$ and physicians $(4.1 \%)$ did so less frequently (Table 3$)$.

\section{Permission}

For most of the participants, the families $(86.6 \%)$ or the participants $(67 \%)$ themselves gave permission to use restraints (Table 4).

\section{Documentation and Evaluation of Restraint Use}

Use of restraints was always $(19.4 \%)$, regularly $(10.3 \%)$, or sometimes $(20 \%)$ documented in the medical record. In $50.3 \%$ of cases, there was no documentation. In $64.5 \%$, restraint use was not evaluated (Table 4).

\section{DISCUSSION}

In the present study, one in four older persons receiving home care was being restrained to some degree, mostly on a daily basis and often for a long time. Comparing these results with those reported in the literature is difficult because of differences between studies in the definition of what constitutes restraint, ${ }^{12,13,25}$ study population, ${ }^{12,13}$ and methodology. ${ }^{14}$ The broad definition of restraints used might partly explain the high prevalence of restraint use observed. At the start of the study, there was a lack of clarity about the definition of restraints in the literature. Based on the results of a qualitative study, ${ }^{15}$ a less-conservative definition of restraints was chosen, one that includes not only physical devices to control behavior, but also 
Table 3. Persons Involved with Initiating, Decision-Making, and Execution of Restraints $(\mathbf{n}=1,577)$

\begin{tabular}{|c|c|c|c|c|c|c|}
\hline \multirow[b]{2}{*}{ Person } & \multicolumn{2}{|c|}{ Initiator } & \multicolumn{2}{|c|}{ Decision-Maker } & \multicolumn{2}{|c|}{ Execution } \\
\hline & n (\%) & $95 \% \mathrm{Cl}$ & n (\%) & $95 \% \mathrm{Cl}$ & n (\%) & $95 \% \mathrm{Cl}$ \\
\hline Patient & $393(24.9)$ & $22.8-27.1$ & 677 (42.9) & $40.5-45.4$ & $\mathrm{n} / \mathrm{a}$ & $\mathrm{n} / \mathrm{a}$ \\
\hline Informal caregiver & $872(55.3)$ & $52.8-57.8$ & $977(62.0)$ & $59.5-64.4$ & $957(60.7)$ & $58.2-63.1$ \\
\hline Nurse & $587(37.2)$ & $34.8-39.7$ & $618(39.2)$ & $36.8-41.6$ & $666(42.2)$ & $39.8-44.7$ \\
\hline Nursing aide & $45(2.9)$ & $2.11-3.8$ & $51(3.2)$ & $2.4-4.2$ & $125(7.9)$ & $6.6-9.4$ \\
\hline Domestic aide & $27(1.7)$ & $1.1-2.5$ & $29(1.8)$ & $1.2-2.6$ & $65(4.1)$ & $3.2-5.2$ \\
\hline Physician & $187(11.9)$ & $10.3-13.6$ & $255(16.2)$ & $14.4-18.1$ & $65(4.1)$ & $3.2-5.2$ \\
\hline Multidisciplinary team & $88(5.6)$ & $4.5-6.8$ & $85(5.4)$ & $4.3-6.6$ & $62(3.9)$ & $3.0-5.0$ \\
\hline Other & $32(2.0)$ & $1.4-2.8$ & $25(1.6)$ & $1.0-2.3$ & $61(3.9)$ & $3.0-4.9$ \\
\hline
\end{tabular}

$\mathrm{CI}=$ confidence interval.

\begin{tabular}{|c|c|}
\hline Restraint use & $n(\%)$ \\
\hline \multicolumn{2}{|l|}{ Permission } \\
\hline \multicolumn{2}{|l|}{ Patient $(\mathrm{n}=1,209)$} \\
\hline oral and written permission & $47(3.9)$ \\
\hline oral permission & $763(63.1)$ \\
\hline $\begin{array}{l}\text { no permission requested, regardless of } \\
\text { ability to do so }\end{array}$ & 134 (11.1) \\
\hline cognitively or physically unable to give permission & $265(21.9)$ \\
\hline \multicolumn{2}{|l|}{ Family $(n=958)$} \\
\hline Written permission & $62(6.5)$ \\
\hline Oral permission & $767(80.1)$ \\
\hline No permission requested & $127(13.3)$ \\
\hline Refusal & $2(0.2)$ \\
\hline \multicolumn{2}{|l|}{ Documentation $(n=1,193)$} \\
\hline Never & $600(50.3)$ \\
\hline Sometimes & $239(20.0)$ \\
\hline Regular & $123(10.3)$ \\
\hline Always & 231 (19.4) \\
\hline \multicolumn{2}{|l|}{ Evaluation of restraint outcome $(n=1,179)$} \\
\hline Never & $760(64.5)$ \\
\hline Daily & $74(6.3)$ \\
\hline Weekly & $72(6.1)$ \\
\hline Monthly & $273(23.2)$ \\
\hline
\end{tabular}

other restrictive actions intended to limit the free movement of older persons being cared for at home (e.g., adaptation of the house, removal of aids). Finding an appropriate definition for restraints is a challenge for researchers in this field. International consensus was recently reached on a research definition of physical restraint in older persons in clinical care settings. ${ }^{26}$ The phrase "involuntary treatment," which includes three categories (physical restraints, psychotropic medication, nonconsensual care) was subsequently introduced. ${ }^{13}$ Further research is necessary to determine whether this classification is more suitable for research on restraints in home care.

Another reason for the high prevalence of restraint use in the current study may be related to informal caregivers. Informal caregivers affect prevalence through their role as initiators, their implicit involvement in the decisionmaking and application processes, and their reasons for applying restraints. Using restraints specifically at the request of the informal caregiver and to give the informal caregiver respite- two reasons also mentioned in the previous study to explain why restraints are used in home care $^{15}$ - strongly suggest that burden placed on the informal caregiver plays a role in deciding whether restraints should be used. The prominent role of informal caregivers in home care may pose some challenges. Research indicates that informal caregivers have less knowledge about the negative consequences of restraint use than professional home care workers ${ }^{27}$ and a more-positive perception of its use. $^{15,28}$ Their role could also explain why most informal caregivers of older adults who are not cognitively impaired also give permission to use restraints. Consistent with previous studies, the current study findings demonstrated that physicians play a rather limited role in the decision-making and application processes for restraint use. ${ }^{14,15}$

Consistent with similar studies performed in other settings, $1,29,30$ safety was the most common reason for using restraints in home care. Given the evidence that restraint use is associated with many negative consequences, ${ }^{1}$ it is doubtful to what extent using restraints guarantees the safety of older adults. Other important reasons for restraint use were to help the individual remain at home longer, which necessitates the use of restraints, and the desire to delay admission to a nursing home. Nurses must be alert to these possibilities and always confirm the desire of the older adults in their care and determine that the decision represents a well-conducted, informed decision-making process that includes identifying other lessrestrictive ways of achieving the goal.

In half of the cases, there was no documentation of restraint use in the medical record. Moreover, in more than six of 10 cases, no evaluation of restraint use or its outcome was documented. The important role of informal caregivers could have contributed to these results. Nevertheless, it is ultimately the nurse's responsibility to evaluate the individual's situation and whether the use of restraints is warranted, to look for less-restrictive measures, and to strive to prevent or decrease restraint use. Moreover, all relevant data about this process need to be documented carefully in the medical record. The lack of a clear definition of restraints and of a restraint policy in the home care organization may have prevented nurses from assuming their responsibility in this process. ${ }^{15}$ Moreover, the lack of knowledge and the insufficient awareness of the nurses about restraint use and its negative consequences ${ }^{15}$ could have influenced the whole process (e.g., prevalence, kind 
of initiators, involvement in the decision-making process, execution of restraints).

Study strengths are the large randomized sample, the carefully developed and validated questionnaire for data collection, the high response rate, and the broad demographic nature of the older population under study. In contrast to existing studies of restraints in home care, the current study included subjects aged 60 and older regardless of their cognitive functioning. ${ }^{12-14}$ This broadens the representativeness of the study in generalizing its findings to the population of older adults receiving professional home care. This study also has limitations. The use of a broad definition of restraints may have influenced the results and should be considered before generalizing them. Because of this less-conservative definition, overall restraint use may have been overestimated. For example, results related to inclusion of bed against the wall as a restraint should be interpreted with caution. Of the 1,577 restrained individuals, 615 were restrained this way; 401 one of these $(65.2 \%)$ were restrained in combination with another type of restraint. As a consequence, and because, in the previous study ${ }^{15}$ nurses perceived this measure as a type of restraint, it is unlikely that this led to a large overestimation. For example, with a hemiplegic individual, a bed against the wall is often used as a restraint when positioning so he or she will not fall out of bed. Furthermore, several measures (e.g., close follow-up, clear instructions to the [head] nurses) were put in place to minimize over- and underreporting.

Another limitation relates to the newly developed questionnaire. Although it was carefully developed, only its content validity was established. Some of the items were based on validated instruments, whereas others were based on a previous study ${ }^{15}$ and insights gleaned from the literature. ${ }^{14}$ Further evaluation of the questionnaire is necessary, and a choice of refusal should be added to the patient decision item.

Twenty percent of the randomized sample was unavailable for data collection (Figure 1), which may have introduced a selection bias, but given the characteristics of the population, most of the reasons for nonparticipation (e.g., death, hospitalization, discharge) were to be expected. Thus, it is likely that there was a low risk of selection bias in the study.

Further research is needed to gain more insight into the experiences of all persons involved in restraints in the home-care setting (e.g., older adults, informal caregivers, nurses, physicians). These insights may contribute to development of guidelines to support all involved, including professionals, with the goal of reducing restraint use.

In conclusion, these results show a high prevalence of restraint use and a range of restraints in home care. Other reasons are given for this practice in the home than in long-term care. Moreover, restraint use in the home care setting seems to have produced another effect, for example, on the role of informal caregivers and the way permission is granted. Because restraint use has negative consequences, it should be discouraged. Nevertheless, if a change in use of restraints in home care is to occur, the process could benefit from better education for caregivers, nurses, and other healthcare providers; a clear policy; interdisciplinary collaboration that includes formal and informal care; and more support for informal caregivers.

\section{ACKNOWLEDGMENTS}

The authors wish to thank the management of the WitGele Kruis for supporting the study and all the home care nurses and colleagues for participating in data collection.

Conflict of Interest: The authors have no conflict of interest.

Author Contributions: Scheepmans, Paquay, Dierckx de Casterlé, Van Gansbeke, Milisen: study design. Scheepmans, Paquay: data collection. Scheepmans, Paquay, Dierckx de Casterlé, Milisen: data analysis, drafting the manuscript. Dierckx de Casterlé, Milisen: supervision. All authors critically reviewed and approved the final manuscript.

Sponsor's Role: The funding agency, Vanbreda Risk \& Benefits, had no role in the design, data collection, analysis, or interpretation of the study.

\section{REFERENCES}

1. Hofmann H, Hahn S. Characteristics of nursing home residents and physical restraint: A systematic literature review. J Clin Nurs 2014;23:30123024.

2. Evans D, Wood J, Lambert L. Patient injury and physical restraint devices: A systematic review. J Adv Nurs 2003;41:274-282.

3. Gastmans C, Milisen K. Use of physical restraint in nursing homes: Clinical-ethical considerations. J Med Ethics 2006;32:148-152.

4. Raguan B, Wolfovitz E, Gil E. Use of physical restraints in a general hospital: A cross-sectional observational study. Isr Med Assoc J 2015;17:633-638.

5. Heinze C, Dassen T, Grittner U. Use of physical restraints in nursing homes and hospitals and related factors: A cross-sectional study. J Clin Nurs 2011;21:1033-1040.

6. Krüger C, Mayer H, Haastert B et al. Use of physical restraints in acute hospitals in Germany: A multi-centre cross-sectional study. Int J Nurs Stud 2013;50:1599-1606.

7. Hofmann H, Schorro E, Haastert B et al. Use of physical restraints in nursing homes: A multicentre cross-sectional study. BMC Geriatr 2015;21:129.

8. Huizing AR, Hamers JP, de Jonge J et al. Organisational determinants of the use of physical restraints: A multilevel approach. Soc Sci Med 2007;65:924-933.

9. Feng Z, Hirdes JP, Smith TF et al. Use of physical restraints and antipsychotic medications in nursing homes: A cross-national study. Int J Geriatr Psychiatry 2009;24:1110-1118.

10. Lodewijck C. Het gebruik van vrijheidsbeperkende maatregelen in Vlaamse algemene ziekenhuizen: Attitude van verantwoordelijken voor het inhoudelijk zorgbeleid. Leuven, Belgium: KU Leuven, 2003.

11. Heeren P, Van de Water G, De Paepe L et al. Staffing levels and the use of physical restraints in nursing homes: A multicenter study. J Gerontol Nurs 2014;40:48-54.

12. Beerens HC, Sutcliffe C, Renom-Guiteras A et al. Quality of life and quality of care for people with dementia receiving long term institutional care or professional home care: The European RightTimePlaceCare study. J Am Med Direc Assoc 2014;15:54-61.

13. Hamers JP, Bleijlevens MH, Gulpers MJ et al. Behind closed doors: Involuntary treatment in care of persons with cognitive impairment at home in the Netherlands. J Am Geriatr Soc 2016;64:354-358.

14. de Veer AJ, Francke AL, Buijse R et al. The use of physical restraints in home care in the Netherlands. J Am Geriatr Soc 2009;57:1881-1886.

15. Scheepmans K, Dierckx de Casterlé B, Paquay L et al. Restraint use in home care: A qualitative study from a nursing perspective. BMC Geriatr 2014;14:17.

16. Morris JN, Fries BE, Mehr DR et al. MDS Cognitive Performance Scale. J Gerontol 1994;49:M174-M182.

17. Landi F, Tua E, Onder G et al. Minimum data set for home care: A valid instrument to assess frail older people living in the community. Med Care 2000;38:1184-1190. 
18. Wellens NI, Flamaing J, Tournoy J et al. Convergent validity of the Cognitive Performance Scale of the interRAI acute care and the Mini-Mental State Examination. Am J Geriatr Psychiatry 2013;21:636-645.

19. Arnaert A, Delesie L. Ijking van meetgegevens: RIZIV ADL-index. Acta Hosp 1999;4:19-31.

20. Steeman E, Moons P, Milisen K et al. Implementation of discharge management for geriatric patients at risk of readmission or institutionalization. Int J Qual Health Care 2006;18:352-358.

21. Milisen K, Coussement J, Flamaing J et al. Fall prediction by nurses' clinical judgment: Differences between medical, surgical, and geriatric wards. J Am Geriatr Soc 2012;60:1115-1121.

22. Hartmaier SL, Sloane PD, Guess HA et al. Validation of the Minimum Data Set Cognitive Performance Scale: Agreement with the Mini-Mental State Examination. J Gerontol A Biol Sci Med Sci 1995;50A:M128-M133.

23. Morris JN, Fries BE, Bernabei R et al. 2010 InterRai Home Care (HC). Assessment form and user's manual. Rockport, Massachusetts, http://train. mede-care.ca/ecareiv/docs/CHA/CHA_Manual.pdf

24. Retsas AP. Survey findings describing the use of physical restraints in nursing homes in Victoria, Australia. Int J Nurs Studies 1998;35:184-191.
25. Bleijlevens M. Restraints Prevalence in Home Care and Nursing Homes: Results from the European RightTimePlaceCare Study. Washington: GSA, 2014.

26. Bleijlevens MH, Wagner LM, Capezuti E. Physical restraints: Consensus of a research definition using a modified Delphi technique. J Am Geriatr Soc 2016;64:2307-2310.

27. Kurata S, Ojima T. Knowledge, perceptions, and experiences of family caregivers and home care providers of physical restraint use with home-dwelling elders: A cross-sectional study in Japan. BMC Geriatr 2014;14:39.

28. Haut A, Kolbe N, Strupeit $S$ et al. Attitudes of relatives of nursing home residents toward physical restraints. J Nurs Scholarsh 2010;42:448-456.

29. Hamers JPH, Huizing AR. Why do we use physical restraints in the elderly? Z Gerontol Geriatr 2005;38:19-25.

30. Evans D, FitzGerald M. Reasons for physically restraining patients and residents: A systematic review and content analysis. Int $\mathrm{J}$ Nurs Stud 2002;39:735-743.

31. Ter Meulen R, Wright K. Family solidarity and informal care: The case of care for people with dementia. Bioethics 2012;26:361-368. 